\title{
Prevalence and diagnostic challenges of thyroid lymphoma: a multi-institutional study in non-Western countries
}

\author{
Mitsuyoshi Hirokawa' ${ }^{1)}$, Ayana Suzuki ${ }^{1)}$, Yuko Hashimoto's), Shinya Satoh ${ }^{3)}$, Sule Canberk ${ }^{4), 5)}$, \\ Jie Yang Jhuang ${ }^{6}$, Chan Kwon Jung ${ }^{7)}$, Nichthida Tangnuntachai ${ }^{8)}$, Bozidar Kovacevic ${ }^{9)}$, Yun Zhu ${ }^{10)}$, \\ Shipra Agarwal ${ }^{11)}$ and Kennichi Kakudo ${ }^{12)}$ \\ 1) Department of Diagnostic Pathology and Cytology, Kuma Hospital, Kobe, Japan \\ 2) Department of Diagnostic Pathology, Fukushima Medical University School of Medicine, Fukushima, Japan \\ 3) Department of Endocrine Surgery, Yamashita Thyroid Hospital, Fukuoka, Japan \\ 4) Department of Pathology, Subdivision of Cytopathology, Acibadem University, Istanbul, Turkey \\ 5) Cancer Signaling \& Metabolism, IPATIMUP/Instituto de Investigação e Inovação em Saúde, Universidade do Porto Rua Alfredo \\ Allen, Porto, Portugal \\ 6) Department of Pathology, Mackay Memorial Hospital, Taipei, Taiwan \\ 7) Department of Hospital Pathology, Seoul St. Mary's Hospital, College of Medicine, The Catholic University of Korea, Seoul, Korea \\ ${ }^{8)}$ King Chulalongkorn Memorial Hospital, Bangkok, Thailand \\ 9) Institute of Pathology and Forensic Medicine, Military Medical Academy, Belgrade, Serbia \\ ${ }^{10)}$ Department of Pathology, Jiangsu Institute of Nuclear Medicine, Wuxi, China \\ 11) Department of Pathology, All India Institute of Medical Sciences, New Delhi, India \\ 12) Department of Pathology and Thyroid Disease Center, Izumi City General Hospital, Izumi, Japan
}

\begin{abstract}
Research on the primary thyroid lymphoma (PTL) diagnosis is limited, with only a few large sample size studies, reported from Asian countries. The aim of the present study was to clarify the current prevalence and challenges in PTL diagnosis, and recommended ancillary studies for PTL in non-Western countries. PTL $(n=153)$ cases were retrieved from 10 institutions in non-Western countries and analyzed. Ultrasound examination (UE) and fine needle aspiration cytology (FNAC) were used as main preoperative diagnostic tools in all participating institutions. Flow cytometry (FCM) was performed in the 5 institutions (50\%). Lobectomy was the most common histological procedure to confirm the PTL diagnosis. All institutions routinely performed immuno-histochemical analysis. PTL was $0.54 \%$ of malignant thyroid tumor cases, with mucosaassociated lymphoid tissue lymphoma (MALTL) and diffuse large B-cell lymphoma (DLBCL) being 54.9\% and 38.6\%, respectively. Kuma Hospital, where the frequency of MALTL was highest (83.7\%), routinely performed FCM using the materials obtained by FNAC. UE and FNAC sensitivities were $62.5 \%$ and $57.8 \%$, respectively. In both UE and FNAC, sensitivity of MALTL was lower than of DLBCL. The study elucidated that the prevalence of PTL in non-Western countries was lower than previously reported. We propose that FCM should be more actively used to improve the preoperative diagnosis of MALTL. Our data predicted that the MALTL proportion will increase with improved diagnostic tools, while observation of PTL-suspected nodules without histological examination remains a viable option.
\end{abstract}

Key words: Thyroid, Lymphoma, Immunohistochemistry, Ancillary study, Aspiration cytology

PRIMARY THYROID LYMPHOMAS (PTLs) are rare, and most cases present as diffuse large B-cell lymphomas (DLBCLs), followed by mucosa-associated lym-

Submitted Apr. 8, 2020; Accepted Jun. 5, 2020 as EJ20-0202

Released online in J-STAGE as advance publication Jul. 9, 2020

Correspondence to: Mitsuyoshi Hirokawa, MD, PhD, FIAC, Department of Diagnostic Pathology and Cytology, Kuma Hospital, 8-2-35 Shimoyamate-dori, Chuo-Ku, Kobe, Hyogo 650-0011, Japan.

E-mail: mhirokawa@kuma-h.or.jp phoid tissue lymphomas (MALTLs) [1-11]. Due to the histological and cytological similarities between thyroid DLBCL and DLBCL arising from other organs, pathological diagnosis of thyroid DLBCL is a simple process. In contrast, diagnosis of thyroid MALTL is more complex, as there may be small-sized nodules, which may represent lymphoma cells of small or various sizes [12]. This subtype is occasionally confused with Hashimoto thyroiditis with high lymphocytic infiltration. The diagnosis is, therefore, made by a combination of histology 
and ancillary studies [12]. Additionally, MALTLs of the thyroid are cytogenetically different from MALTLs of other organs [13]. These factors lead to considerable interobserver variability in the diagnosis of thyroid MALTLs.

Most of the reports on the diagnosis of PTL are sporadic, and studies using a large sample size are few, particularly in Asian countries. A multi-institutional study on PTL was proposed by The Asian Working Group in Thyroid Cytology (TAWGTC) network [14]. The current study is based on data compiled from 10 institutions in nonWestern countries. The aim of this report was to clarify the current prevalence and diagnostic challenges of PTL, and recommended ancillary studies for PTL in nonWestern countries.

\section{Materials and Methods}

TAWGTC proposed the current study on PTL and recruited the participating institutions. The eligibility for participation was to have an experience diagnosing at least 5 PTL cases over the last decade. PTL was defined as a lymphoma involving only the thyroid, or the thyroid and its adjacent lymph nodes (stages IE or IIE, respectively, under the Ann Arbor staging system). In the latter cases, the thyroid lesions were larger than or appeared before those in the lymph nodes. Dissemination to the other organs was excluded by clinical evaluation, ultrasound examination (UE), PET/CT imaging, and/or bone marrow biopsy. One case with stage IV lymphoma was considered as PTL because the thyroid lesion was the first to appear. A questionnaire on PTL diagnosis was distributed. Ten institutions in non-Western countries were selected to participate: 1) Kuma Hospital (Japan), 2) Fukushima Medical University School of Medicine (Japan), 3) Yamashita Thyroid Hospital (Japan), 4) Acibadem University (Turkey), 5) Mackay Memorial Hospital (Taiwan), 6) The Catholic University of Korea (Korea), 7) King Chulalongkorn Memorial Hospital (Thailand), 8) Military Medical Academy (Serbia), 9) Jiangsu Institution of Nuclear Medicine (China), and 10) All India Institute of Medical Sciences (India). Annual malignant thyroid tumor cases from each institution ranged from 57 to 1,326 cases (Table 1). The institutions were classified into two groups, high $(>500$ malignant thyroid surgical cases/yr) and low ( $<500$ cases/yr) volume centers. In total, 153 PTL cases were retrieved from the 10 institutions, and the diagnostic significance and challenges were examined.

Table 1 Prevalence of thyroid lymphoma in 10 participating institutions

\begin{tabular}{|c|c|c|c|c|c|c|c|c|c|c|c|}
\hline \multicolumn{4}{|c|}{ Sources } & \multirow[b]{2}{*}{ Period } & \multirow{2}{*}{$\begin{array}{c}\text { Surgical } \\
\text { thyroid } \\
\text { cases } \\
(47,339)\end{array}$} & \multirow{2}{*}{$\begin{array}{l}\text { Malignant } \\
\text { thyroid tumor } \\
\text { cases } \\
(28,168) \\
(/ \mathrm{yr})\end{array}$} & \multicolumn{5}{|c|}{ Lymphomas } \\
\hline & Participants & Institutions & City, Country & & & & $\begin{array}{c}\text { Total } \\
153 \\
(0.5 \%)\end{array}$ & $\begin{array}{c}\text { MALT } \\
84 \\
(54.9 \%)\end{array}$ & $\begin{array}{c}\text { DLBCL } \\
59 \\
(38.6 \%)\end{array}$ & $\begin{array}{c}\text { FL } \\
3 \\
(2.0 \%)\end{array}$ & $\begin{array}{l}\text { Others* } \\
7 \\
(4.6 \%)\end{array}$ \\
\hline A & $\begin{array}{l}\text { Suzuki, A \& } \\
\text { Hirokawa, M }\end{array}$ & Kuma Hospital & Kobe, Japan & $\begin{array}{l}2015.1- \\
2017.12\end{array}$ & 4,902 & $\begin{array}{l}2,926 \\
(975)\end{array}$ & $\begin{array}{c}43 \\
(1.5 \%)\end{array}$ & 36 & 7 & 0 & 0 \\
\hline $\mathrm{B}$ & Hashimoto, Y & $\begin{array}{c}\text { Fukushima Medical } \\
\text { University }\end{array}$ & $\begin{array}{l}\text { Fukushima, } \\
\text { Japan }\end{array}$ & $\begin{array}{c}2003.1- \\
2019.7\end{array}$ & 1,750 & $\begin{array}{l}916 \\
(57)\end{array}$ & $\begin{array}{c}28 \\
(3.1 \%)\end{array}$ & 9 & 19 & 0 & 0 \\
\hline $\mathrm{C}$ & $\begin{array}{c}\text { Sato, S \& } \\
\text { Kakudo, K }\end{array}$ & $\begin{array}{c}\text { Yamashita Thyroid } \\
\text { Hospital }\end{array}$ & Fukuoka, Japan & $\begin{array}{c}2013.10 \\
2018.12\end{array}$ & 4,382 & $\begin{array}{l}2,556 \\
(511)\end{array}$ & $\begin{array}{c}30 \\
(1.2 \%)\end{array}$ & 22 & 7 & 0 & 1 \\
\hline $\mathrm{D}$ & Canberk, S & $\begin{array}{c}\text { Acibadem University } \\
\text { \& IPATIMUP }\end{array}$ & $\begin{array}{l}\text { Istanbul, Turkey } \\
\& \text { Port, Portugal }\end{array}$ & $\begin{array}{c}2009.5- \\
2019.5\end{array}$ & 10,884 & $\begin{array}{l}6,934 \\
(630)\end{array}$ & $\begin{array}{c}9 \\
(0.1 \%)\end{array}$ & 1 & 5 & 2 & 1 \\
\hline $\mathrm{E}$ & Jhuang, JY & $\begin{array}{c}\text { Mackay Memorial } \\
\text { Hospital }\end{array}$ & Taipei, Taiwan & $\begin{array}{c}2009.1- \\
2019.6\end{array}$ & 805 & $\begin{array}{l}753 \\
(68)\end{array}$ & $\begin{array}{c}6 \\
(0.8 \%)\end{array}$ & 2 & 3 & 0 & 1 \\
\hline $\mathrm{F}$ & Jung, CK & $\begin{array}{c}\text { Catholic University of } \\
\text { Korea \& St. Mary's } \\
\text { Hospital Seoul }\end{array}$ & Seoul, Korea & $\begin{array}{l}2013.1- \\
2015.12\end{array}$ & 2,643 & $\begin{array}{l}2,507 \\
(836)\end{array}$ & $\begin{array}{c}6 \\
(0.2 \%)\end{array}$ & 1 & 4 & 0 & 1 \\
\hline G & Tangnuntachai, $\mathrm{N}$ & $\begin{array}{l}\text { King Chulalongkorn } \\
\text { Memorial Hospital }\end{array}$ & $\begin{array}{l}\text { Bangkok, } \\
\text { Thailand }\end{array}$ & $\begin{array}{c}2009.1- \\
2019.1\end{array}$ & 6,248 & $\begin{array}{l}2,019 \\
(202)\end{array}$ & $\begin{array}{c}7 \\
(0.3 \%)\end{array}$ & 2 & 4 & 0 & 1 \\
\hline $\mathrm{H}$ & Kovacevic, B & $\begin{array}{c}\text { Military Medical } \\
\text { Academy }\end{array}$ & Belgrade, Serbia & $\begin{array}{l}2013.1- \\
2018.12\end{array}$ & 1,829 & $\begin{array}{c}909 \\
(152)\end{array}$ & $\begin{array}{c}5 \\
(0.6 \%)\end{array}$ & 3 & 1 & 0 & 1 \\
\hline I & Yun, Z & $\begin{array}{l}\text { Jiangsu Institution of } \\
\text { Nuclear Medicine }\end{array}$ & Wuxi, China & $\begin{array}{l}2013.1- \\
2018.12\end{array}$ & 12,431 & $\begin{array}{c}7,958 \\
(1,326)\end{array}$ & $\begin{array}{c}8 \\
(0.1 \%)\end{array}$ & 5 & 2 & 1 & 0 \\
\hline $\mathrm{J}$ & Agarwal, S & $\begin{array}{l}\text { All India Institute of } \\
\text { Medical Sciences }\end{array}$ & New Delhi, India & $\begin{array}{c}2009.1- \\
2015.3\end{array}$ & 1,465 & $\begin{array}{c}690 \\
(115)\end{array}$ & $\begin{array}{c}11 \\
(1.6 \%)\end{array}$ & 3 & 7 & 0 & 1 \\
\hline
\end{tabular}

DLBCL, Diffuse large B-cell lymphoma; FL, Follicular lymphoma; MALT, Mucosa-associated lymphoid tissue lymphoma.

* Burkitt, Mantle zone, Anaplastic large T cell, Hodgkin, and Unclassified lymphomas, and Plasmacytoma. 
Statistical analyses were performed using the Stat Flex v.6 statistical software (Artech Co., Ltd, Osaka, Japan). Values of $p<0.05$ were regarded as statistically significant in the Fisher probability test and Student's $t$-test.

\section{Results}

\section{Prevalence}

Of the 28,168 thyroid malignant tumors histologically diagnosed in the 10 participating institutions, 153 $(0.54 \%)$ were PTL (Table 1$)$. The incidence in each institution ranged from $0.1 \%$ to $3.1 \% ; 4$ institutions (40\%) had an incidence rate of less than $0.5 \%$. The incident rates were not related to the volume of thyroid malignant cases at the institutions. All of the Japanese and Indian institutions exhibited high incidence rates (more than 1\%). Among PTLs, 84 cases (54.9\%) were MALTL, followed by DLBCL (59 cases, 38.6\%). The predominance of MALTL was seen in 4 institutions (2 Japanese, 1 Serbian and 1 Chinese institutions), 3 of which were high volume centers; Kuma Hospital, Japan had the highest incidence of MALTL (83.7\%). The remaining lymphomas included 3 follicular lymphomas, 1 Burkitt lymphoma, 1 mantle zone lymphoma, 1 anaplastic large $\mathrm{T}$ cell lymphoma, 1 Hodgkin lymphoma, 1 plasmacytoma, and 2 unclassified lymphomas. In 129 cases with preoperative examination of Hashimoto thyroiditisrelated autoantibodies, $108(83.7 \%)$ were positive. The frequency in MALTL cases was higher than that in DLBCL cases $(91.0 \%$ versus $75.6 \%)$.

\section{Preoperative diagnosis}

In addition to histological examination, diagnostic modalities included UE, fine needle aspiration cytology (FNAC), and flow cytometry (FCM). UE and FNAC were used as main preoperative diagnostic tools in all participating institutions (Table 2). FCM was performed in the 5 institutions (50\%). Among them, only Kuma Hospital, where the frequency of MALTL was the highest, routinely performed FCM using samples obtained by FNAC. The other four institutions occasionally or rarely performed FCM. The remaining 5 institutions did not perform FCM. Table 3 shows the results of the original preoperative UE reports. The frequencies of benign, intermediate, and high suspicion were 19.5\%, 18.0\%, and $62.5 \%$ respectively. The sensitivity of DLBCLs $(86.4 \%)$ was significantly higher than that of MALTLs (48.1\%) $(p<0.05)$. Of 77 MALTLs, $19(24.7 \%)$ were interpreted as benign. Both sensitivity $(61.4 \%)$ and falsenegative rate $(27.3 \%)$ of UE in small volume centers tended to be higher than those in high volume centers (52.4\% and $15.5 \%$, respectively); however, these differences were not statistically significant. Table 4 shows the results of the original preoperative FNAC reports. Of 116 PTLs with FNAC, 67 (57.8\%) were reported as suspicious for malignancy or malignant. Sensitivities of MALTL and DLBCL were $45.2 \%$ and $76.9 \%$, respectively. MALTLs reported as benign and atypia of undetermined significance (AUS), were $20.5 \%$ and $31.5 \%$, respectively. Once more, both sensitivity $(61.5 \%)$ and false-negative rate $(17.9 \%)$ of FNAC in small volume centers tended to be higher than those in high volume centers (55.8\% and $13.0 \%$, respectively); however, these differences were not statistically significant. In 4 institutions (40\%), observation without histological examination of PTL-suspected nodules was an available option.

\section{Histological diagnosis}

To confirm the diagnosis of lymphoma, histological examination was required by all institutions. Lobectomy was the most common procedure (Table 2). One institution did not perform core needle biopsies, because it was difficult to distinguish early stage MALTL from Hashimoto thyroiditis with high lymphocytic infiltration, and ancillary studies were limited. For large-sized lesions or DLBCL-suspected lesions, core needle biopsy or open biopsy were often indicated. Based on the questionnaire,

Table 2 Diagnostic procedures for thyroid lymphoma-suspected cases in 10 participating institutions

\begin{tabular}{lccc}
\hline & Often to Always* & Occasionally to Sometimes** & Never to Rarely*** \\
\hline Ultrasound & 10 & 0 & 0 \\
Cytology & 9 & 1 & 0 \\
Flow cytometry & 1 & 4 & \\
Histological examinations & & & 1 \\
$\quad$ Core needle biopsy & 3 & 6 & 3 \\
$\quad$ Open biopsy & 1 & 2 & 2 \\
$\quad$ Lobectomy & 6 & 5 & 2 \\
$\quad$ Thyroidectomy & 3 & &
\end{tabular}


Table 3 Preoperative ultrasound reports for 128 thyroid lymphoma cases

\begin{tabular}{lccc}
\hline & Benign & Borderline & Suspicious for malignancy or Malignant \\
\hline MALT (77) & $19(24.7 \%)$ & $21(27.3 \%)$ & $37(48.1 \%)$ \\
DLBCL (44) & $5(11.4 \%)$ & $1(2.3 \%)$ & $38(86.4 \%)$ \\
FL (3) & $0(0 \%)$ & $1(33.3 \%)$ & $2(66.7 \%)$ \\
Others (4) & $1(25.0 \%)$ & $0(0 \%)$ & $3(75.0 \%)$ \\
Total (128) & $25(19.5 \%)$ & $23(18.0 \%)$ & $80(62.5 \%)$ \\
\hline
\end{tabular}

DLBCL, Diffuse large B-cell lymphoma; FL, Follicular lymphoma; MALT, Mucosa-associated lymphoid tissue lymphoma.

Table 4 Preoperative cytological reports for 116 thyroid lymphoma cases

\begin{tabular}{lccccc}
\hline & ND/UNS & Benign & AUS/FLUS & FN/SFN & SFM \& Malignant \\
\hline MALTL (73) & $1(1.4 \%)$ & $15(20.5 \%)$ & $23(31.5 \%)$ & $1(1.4 \%)$ & $33(45.2 \%)$ \\
DLBCL (39) & $3(7.7 \%)$ & $2(5.1 \%)$ & $4(10.3 \%)$ & $0(0 \%)$ & $30(76.9 \%)$ \\
Others (4) & $0(0 \%)$ & $0(0 \%)$ & $0(0 \%)$ & $0(0 \%)$ & $4(100 \%)$ \\
Total (116) & $4(3.4 \%)$ & $17(14.7 \%)$ & $27(23.3 \%)$ & $1(0.9 \%)$ & $67(57.8 \%)$ \\
\hline
\end{tabular}

AUS/FLUS, Atypia of undetermined significance or follicular lesion of undetermined significance; DLBCL, Diffuse large B-cell lymphoma; FN/SFN, Follicular neoplasm or suspicious for a follicular neoplasm; MALTL, Mucosa-associated lymphoid tissue lymphoma; ND/UNS, Nondiagnostic or Unsatisfactory; SFM, Suspicious for malignancy.

the most reliable pathological findings for diagnosing PTL were monotonous lymphocytic proliferation (nodular lesions consisting only of lymphocytes without epithelial cells) and lymphoepithelial lesions, followed by packing and follicular colonization. Extrathyroidal extension was not significant. There was consensus that the above findings were useful in distinguishing MALTL from Hashimoto thyroiditis. The presence of the follicles composed of Hürthle cells permeated by small lymphocytes indicated Hashimoto thyroiditis. In contrast, the follicular cells composing lymphoepithelial lesions and packing seen in lymphoma were not Hürthle cells. Large-sized lymphoma cells (more than 3 times the size of small lymphocytes), mitosis, apoptotic cells, no follicular cells, necrosis, and high Ki-67 labeling index favor DLBCL rather than MALTL. The term "plasmacytoma" was not used for thyroid. It was difficult to distinguish between MALTL with prominent plasmocytic differentiation from plasmacytoma, because cases with pure plasma cell proliferation can also display similar histological features of MALTL, including packing, lymphoepithelial lesions, and follicular colonization.

\section{Ancillary studies}

An immunohistochemical study using various antibodies was performed by all institutions and B-cell markers, T-cell markers, and follicular dendritic cell markers were used (Table 5). Follicular dendritic cell markers, such as $\mathrm{CD} 21, \mathrm{CD} 23$, and $\mathrm{CD} 35$, were used to detect the disappearance of follicular dendritic cell meshwork, indicating follicular colonization. To determine light chain restriction, antibodies for kappa and lambda were used in 9 institutions (90\%). Cytokeratins were used to highlight lymphoepithelial lesions and packing in 9 institutions (90\%). In 6 institutions $(60 \%)$, the Hans' classification was performed for DLBCLs. From the 40 DLBCLs examined by this method, 19 and 21 were the germinal center B-cell-like (GCB) and activated B-celllike (ABC) subtypes, respectively. FCM based on CD45 and side scatter-based gating, IgH rearrangement analysis using southern blotting, and karyotypic analysis (Gbanding chromosomal examination) were done in 5,3 , and 3 institutions, respectively.

\section{Discussion}

PTLs represent approximately 0.4 to $5 \%$ of all thyroid malignant tumors according to reports from Western countries [1-11]. In the present study, we showed that the incidence of PTLs in 10 non-Western participating institutions was $0.54 \%$. The incidence in each institution ranged between $0.1 \%$ to $3.1 \%$, and 4 institutions $(40 \%)$ reported incidences of less than $0.5 \%$. This demonstrated that the incidence of PTLs in non-Western countries may be lower than in the Western countries. The geographic variation in the incidence of lymphoma has previously been shown in the literature to be higher in the Western countries, and lower in Asia and Africa [15]. With the 
Table 5 Ancillary studies for diagnosing thyroid lymphoma, performed in 10 participating institutions

\begin{tabular}{|c|c|c|}
\hline \multicolumn{3}{|l|}{ Immunohistochemical study } \\
\hline B-cell markers & $(10)$ & CD10 (10), CD19 (1), CD20 (10), CD79a (5), CD138 (1), PAX5 (2) \\
\hline Immunoglobulins & (9) & Light chain (9), Heavy chain (3) \\
\hline T-cell markers & $(10)$ & CD3 (9), CD5 (9), UCHL1 (1) \\
\hline Follicular dendritic cell markers & $(10)$ & CD21 (3), CD23 (6), CD35 (1) \\
\hline Others & & CD30 (5), CD43 (5), BCL2 (6), BCL6 (4), MUM1 (3), EBER (3), Cyclin D1 (4) \\
\hline Epithelial marker (Cytokeratin) & (9) & \\
\hline Proliferation marker (Ki-67) & (3) & \\
\hline Flow cytometry & (5) & \\
\hline IgH rearrangement & (3) & \\
\hline Karyotypic examinations & (3) & \\
\hline FISH, chromosome 3 & (1) & \\
\hline
\end{tabular}

current study, our group demonstrated that PTLs followed the same trend.

Hashimoto thyroiditis is considered a risk factor of PTLs, especially MALTL. More than $90 \%$ of patients with PTL have elevated circulating thyroidal autoantibodies [16]. In the current study, $83.7 \%$ of PTL cases revealed Hashimoto thyroiditis-related autoantibodies. As expected, the frequency in MALTL cases was higher than that in DLBCL cases $(91.0 \%$ and $75.6 \%$, respectively).

Almost all PTLs are from the B-cell lineage, and several reports have described that DLBCL was the most common subtype $(>60 \%)$, followed by MALTL (10$30 \%)$ and FL (2-10\%) [1-11]. In the current study, however, the predominant subtype was MALTL, and the highest rate of incidence among the institutions was $83.7 \%$. Three of four institutions with MALTL predominance were high volume centers. As DLBCLs frequently contain the components of MALTL, they are speculated to be transformed from pre-existing MALTLs [6]. The cause could be due to earlier detection of MALTLs by improved diagnostic accuracies of the UE, FNAC, and ancillary studies $[12,13]$. In fact, a recent trend indicated towards an increasing proportion of MALTL [12, 13, 17]. However, the possible involvement of racial and/or environmental factors cannot be ruled out.

UE is the primary imaging modality used to detect PTL, and typically shows 3 patterns: nodular, diffuse, and mixed [18]. UE was used as a main preoperative diagnostic tool in all participating institutions. Hirokawa et al. reported 32 PTL cases with UE, and the sensitivity was $62.5 \%$ [12]. In our samples, the sensitivity was $62.5 \%$. The sensitivity of MALTL (48.1\%) was lower than that of DLBCL (86.4\%). Of MALTL cases, $24.7 \%$ were interpreted as benign. The early and accurate detection of MALTL using UE should be addressed in future studies.
The next step in diagnosing PTL is to perform FNAC. In 9 of 10 institutions, FNAC was performed as the main diagnostic tool. The remaining institute preferred core needle biopsy rather than FNAC. According to the review of 593 PTL cases by Zhang et al., the sensitivity of FNAC was $48.0 \%$ [19]. In our samples, the sensitivity was $57.8 \%$. Of the MALTL cases, $20.5 \%$ were classified as benign, since MALTL is composed of heterogeneous cells and may be confused with Hashimoto thyroiditis with high lymphoid proliferation. In addition, MALTL is usually associated with Hashimoto thyroiditis. The diagnosis of DLBCL is simpler due to the presence of large monotonous atypical cells. The diagnostic accuracy of FNAC for PTL significantly depended on the proportion of MALTL and DLBCL cases in the samples. According to the Bethesda system, when PTL is suspected in FNAC, a repeat aspirate for FCM is recommended [20]. The pre-operative FCM using aspirated materials has the same diagnostic accuracy as using resected materials [13]. Stacchini et al. reported that the combination of cytology and FCM showed sensitivity and specificity of $100 \%$ [21]. Among our participating institutions, the one where the proportion of MALTL was the highest preoperatively performed FCM using the aspirated materials from all lymphoma suspected nodules [12]. We propose that FCM should be more actively used to improve the preoperative diagnosis of MALTL.

A histological examination was generally performed for suspected PTL nodules from the FNAC. In our series, a lobectomy was the most common procedure. For largesized or DLBCL-suspected lesions, a core needle biopsy or open biopsy might be indicated. One institution did not perform core needle biopsies, because it was difficult to distinguish early stage MALTL from Hashimoto thyroiditis with high lymphocytic infiltration, and ancillary studies were limited. Therefore, there is a possibility that 
histological examination by core needle biopsy may overlook early stage MALTL.

To confirm the diagnosis of PTL, immunohistochemical testing is necessary [10]. Monotonous lymphocytic proliferation is demonstrated by solid proliferation of lymphoid cells expressing B-cell marker (CD20). For lymphoma with plasma cell differentiation, the demonstration of light chain restriction using antibodies against kappa and lambda is useful [22]. Cytokeratins were used to highlight lymphoepithelial lesion and packing. Follicular dendritic cell markers, either CD21 or $\mathrm{CD} 23$, were used to demonstrate follicular colonization in most of the institutions. Hans' classification markers, such as BCL 6 and MUM1, were used by $30 \%$ of the institutions. Thus, the minimum required immunohistochemical panel to diagnose PTL should include B-cell markers, T-cell markers, light chains, cytokeratins, and follicular dendritic cell markers.

Other ancillary studies, including FCM, IgH rearrangement, and karyotypic analyses, may provide important information for the diagnosis, classification and biological behaviors of lymphomas [12, 13, 20]. Suzuki et al. examined 110 PTL cases and reported that the positive rates of light chain restriction, heavy chain DNA rearrangement, and chromosomal abnormalities were $69.2 \%, 65.4 \%$, and $49.0 \%$, respectively [13]. The negative rate for all three studies was 3.8\%. Although the ancillary studies were useful and should be adopted more actively, their utilization was not common in nonWestern countries.

Spontaneous regression of PTL has rarely been reported $[23,24]$. Nakao et al. reported that 12 of 22 hypoechoic thyroid lesions that were possibly PTLs based on UE and FNAC, decreased in size or disappeared during careful observation [25]. Thus, observation without histological diagnostic procedures can be considered an option for PTL-suspected nodules. This approach was adopted by 4 (2 Japanese, 1 Thai, and 1 Chinese institutions) of 10 institutions. We expect that the indication for and significance of careful observation of PTL-suspected nodules will be established in the future.

\section{Conclusion}

The cause that the predominant subtype was MALTL could be due to earlier detection of MALTLs by improved diagnostic accuracies of the UE, FNAC, and ancillary studies. We demonstrated that the incidence of PTLs in non-Western countries may be lower than in the Western counties. The early and accurate detection of MALTL using UE should be addressed in future studies. We propose that FCM should be more actively used to improve the preoperative diagnosis of MALTL. The minimum required immunohistochemical panel to diagnose PTL should include B-cell markers, T-cell markers, light chains, cytokeratins, and follicular dendritic cell markers. Although the ancillary studies were useful and should be adopted more actively, their utilization was not common in non-Western countries. We expect that the indication for and significance of careful observation of PTL-suspected nodules will be established in the future.

\section{Acknowledgement}

The authors wish to thank Dr. Akira Miyauchi, Department of Surgery, Kuma Hospital, for commenting a draft of this manuscript.

\section{Statement of Ethics}

No ethical approval was obtained because this study did not involve a prospective evaluation or laboratory animals, and only involved non-invasive procedures.

\section{Disclosure Statement}

The authors have no disclosures to make. No funding was received for this study.

\section{Author Contributions}

Conceptualization and methodology: M. Hirokawa; Case presentation and questionnaire responses: All authors; Data processing: A. Suzuki; Original draft preparation and writing: M. Hirokawa; Draft review and editing: A. Suzuki; Supervision: K. Kakudo.

\section{References}

1. Sharma A, Jasim S, Reading CC, Ristow KM, Villasboas Bisneto JC, et al. (2016) Clinical presentation and diagnostic challenges of thyroid lymphoma: a cohort study. Thyroid 26: 1061-1067.
2. Adhikari LJ, Reynolds JP, Wakely PE Jr (2016) Multiinstitutional study of fine-needle aspiration for thyroid lymphoma. J Am Soc Cytopathol 5: 170-176.

3. Noble VV, Ermann DA, Griffin EK, Silberstein PT (2019) 
Primary thyroid lymphoma: an analysis of the National Cancer Database. Cureus 11: e4088.

4. Pavlidis ET, Pavlidis TE (2019) A Review of primary thyroid lymphoma: molecular factors, diagnosis and management. J Invest Surg 32: 137-142.

5. Walsh S, Lowery AJ, Evoy D, McDermott EW, Prichard RS (2013) Thyroid lymphoma: recent advances in diagnosis and optimal management strategies. Oncologist 18: 994-1003.

6. Stein SA, Wartofsky L (2013) Primary thyroid lymphoma: a clinical review. J Clin Endocrinol Metab 98: 3131-3138.

7. Mehta K, Liu C, Raad RA, Mitnick R, Gu P, et al. (2015) Thyroid lymphoma: a case report and literature review. World J Otorhinolaryngol 5: 82-89.

8. Kakkar A, Purkait S, Agarwal S, Mallick S, Gogia A, et al. (2019) Primary thyroid lymphoma: a series from a tertiary care center in Northern India. $J$ Cancer Res Ther 15: 669-675.

9. Widder S, Pasieka JL (2004) Primary thyroid lymphomas. Curr Treat Options Oncol 5: 307-313.

10. Derringer GA, Thompson LD, Frommelt RA, Bijwaard KE, Heffess CS, et al. (2000) Malignant lymphoma of the thyroid gland: a clinicopathologic study of 108 cases. $\mathrm{Am}$ J Surg Pathol 24: 623-639.

11. Nam M, Shin JH, Han BK, Ko EY, Ko ES, et al. (2012) Thyroid lymphoma: correlation of radiologic and pathologic features. J Ultrasound Med 31: 589-594.

12. Hirokawa M, Kudo T, Ota H, Suzuki A, Kobayashi K, et al. (2017) Preoperative diagnostic algorithm of primary thyroid lymphoma using ultrasound, aspiration cytology, and flow cytometry. Endocr J 64: 859-865.

13. Suzuki A, Hirokawa M, Higashiyama T, Fukata S, Takada $\mathrm{N}$, et al. (2019) Flow cytometric, gene rearrangement, and karyotypic analyses of 110 cases of primary thyroid lymphoma: a single-institutional experience in Japan. Endocr J 66: 1083-1091.

14. Bychkov A, Kakudo K, Hong S (2017) Current practices of thyroid fine-needle aspiration in Asia: a missing voice. J Pathol Transl Med 51: 517-520.

15. Huh J (2012) Epidemiologic overview of malignant lym- phoma. Korean J Hematol 47: 92-104.

16. Noureldine SI, Tufano RP (2015) Association of Hashimoto's thyroiditis and thyroid cancer. Curr Opin Oncol 27: 21-25.

17. Watanabe N, Noh JY, Narimatsu H, Takeuchi K, Yamaguchi T, et al. (2011) Clinicopathological features of 171 cases of primary thyroid lymphoma: a long-term study involving 24553 patients with Hashimoto's disease. Br J Haematol 153: 236-243.

18. Ota H, Ito Y, Matsuzuka F, Kuma S, Fukata S, et al. (2006) Usefulness of ultrasonography for diagnosis of malignant lymphoma of the thyroid. Thyroid 16: 983-987.

19. Zhang L, Castellana M, Virili C, Crescenzi A, Giorgino F, et al. (2019) Fine-needle aspiration to diagnose primary thyroid lymphoma: a systematic review and metaanalysis. Eur J Endocrinol 180: 177-187.

20. Cibas ES, Ali SZ (2017) The 2017 Bethesda system for reporting thyroid cytopathology. Thyroid 27: 1341-1346.

21. Stacchini A, Pacchioni D, Demurtas A, Aliberti S, Cassenti A, et al. (2015) Utilility of flow cytometry as ancillary study to improve the cytologic diagnosis of thyroid lymphomas. Cytometry B Clin Cytom 88: 320-329.

22. Kojima M, Shimizu K, Shimizu K, Masawa N (2009) Incidental MALT type lymphoma exhibiting prominent plasma cell differentiation associated with Hashimoto's thyroiditis. A two case report. Head Neck Pathol 3: 27-30.

23. Illán-Gambín F, Manresa-Manresa $\mathrm{P}$, Rodríguez-Aleo E, Aranda-López I (2020) Spontaneous regression of primary thyroid lymphoma: two rarities at the same time. Turk Patoloji Derg 36: 164-168.

24. Uohashi A, Imoto S, Matsui T, Murayama T, Okimura Y, et al. (1996) Spontaneous regression of diffuse large-cell lymphoma associated with Hashimoto's thyroiditis. Am J Hematol 53: 201-202.

25. Nakao T, Nishikawa M, Hisakado M, Kasahara T, Kudo $\mathrm{T}$, et al. (2018) Characteristics and natural course of hypoechoic thyroid lesions diagnosed as possible thyroid lymphomas by fine needle aspiration cytology. Thyroid Res 11: 8 . 